\title{
Article \\ Structural Identification and Coagulation Effect of Flammulina velutipes Polysaccharides
}

\author{
Zhenhua Liang ${ }^{1,2,+} \oplus$, Kangwei Zheng ${ }^{1,2,+}$, Qingchun Zhao ${ }^{1,2}$, Wenjing Shao ${ }^{1,2}$, Changqin Li ${ }^{1,2,3}$, \\ Jinmei Wang 1,2,*, Changyang Ma ${ }^{1,2,3, *}$ and Wenyi Kang 1,2,3,* \\ 1 National R \& D Center for Edible Fungus Processing Technology, Henan University, Kaifeng 475004, China; \\ liangzhenhua@henu.edu.cn (Z.L.); 18522047@sqmc.edu.cn (K.Z.); qingchun188646@163.com (Q.Z.); \\ jj592633@outlook.com (W.S.); lcq@vip.henu.edu.cn (C.L.) \\ 2 Joint International Research Laboratory of Food \& Medicine Resource Function, Kaifeng 475004, China \\ 3 Functional Food Engineering Technology Research Center of Henan Province, Kaifeng 475004, China \\ * Correspondence: wangjinmei@henu.edu.cn (J.W.); macaya1024@vip.henu.edu.cn (C.M.); \\ kangwenyi@henu.edu.cn (W.K.); Tel.: +86-371-23880680 (W.K.) \\ $+\quad$ These authors contributed equally to this work.
}

check for updates

Citation: Liang, Z.; Zheng, K.; Zhao, Q.; Shao, W.; Li, C.; Wang, J.; Ma, C.; Kang, W. Structural Identification and Coagulation Effect of Flammulina velutipes Polysaccharides. Appl. Sci. 2021, 11, 1736. https://doi.org/ 10.3390/app11041736

Academic Editor: Gohar Khachatryan

Received: 27 January 2021

Accepted: 11 February 2021

Published: 16 February 2021

Publisher's Note: MDPI stays neutral with regard to jurisdictional claims in published maps and institutional affiliations.

Copyright: (c) 2021 by the authors. Licensee MDPI, Basel, Switzerland. This article is an open access article distributed under the terms and conditions of the Creative Commons Attribution (CC BY) license (https:/ / creativecommons.org/licenses/by/ $4.0 /)$.

\begin{abstract}
Two polysaccharides were isolated successfully from Flammulina velutipes and identified as CHFVP-1 (24.44 kDa) and CHFVP-2 (1497 kDa). Based on the results of Fourier transform-infrared spectroscopy (FT-IR), gas chromatography (GC), gas chromatography-mass spectrometry (GC-MS), and nuclear magnetic resonance (NMR) spectroscopy regarding the structure of CHFVP-1 and CHFVP-2, CHFVP-1 was constructed with the backbone of $\rightarrow 6)-\alpha-\mathrm{D}-\mathrm{Gal} p-(1 \rightarrow$ and the branch of Gal $p$ by an $\rightarrow 3,6)-\alpha$-D-Man $p$-( $1 \rightarrow$ attached with T- $\beta$-D-Glc $p$ or $\mathrm{t}-\alpha$-L-Fuc $p$ side chains. Meanwhile, the CHFVP-2 was a glucan with the construction of $\rightarrow 6)-\beta-\mathrm{D}-\mathrm{Gl} c p-(1 \rightarrow$ and T- $\beta$-D-Glc $p$. Moreover, the coagulant activity in vitro of CHFVP-1 and CHFVP-2 was evaluated, and the results showed that CHFVP-1 exerts procoagulant activity by shortening the activated partial thromboplastin time (APTT) and thrombin time (TT), while CHFVP-2 did not reveal a definite coagulant activity. The finding would benefit the further application of F. velutipes in the field of medicine.
\end{abstract}

Keywords: polysaccharides; Flammulina velutipes; identification; coagulation effect

\section{Introduction}

Flammulina velutipes, one of the edible mushrooms of Flammulina, is popular in Asia, North America, and Europe, and its production and consumption have increased rapidly due to its rich nutritional values and industrialized cultivation [1]. According to the finding of many researchers, polysaccharides, well-known key functional compounds in F. velutipes fruit bodies, have a variety of bioactivities, such as immunomodulatory [2], antitumor [3], antioxidant [4], anti-proliferation [5], anti-Hepatitis B Virus(HBV) activity [6], hepatocyte protection [7], renoprotective effects [8], and so on.

In our previous study, we found that several polysaccharides have coagulation or anticoagulation activities [9-12]. Up to date, there is no research on the coagulation effect of the F. velutipes polysaccharides. In this study, the crude polysaccharides, CHFVP-1 and CHFVP-2, were extracted, isolated, and purified from F. velutipes. Then, the relative molecular weight, physical and chemical properties, monosaccharide composition, residue segments, linkages, and the possible primary structure of the two F. velutipes polysaccharides were analyzed with corresponding methods. Meanwhile, the coagulation activity of the purified F. velutipes polysaccharides was studied in vitro.

\section{Materials and Methods}

\subsection{Materials}

F. velutipes sample were dried, ground, and collected from Henan Lonfon Industrial Corporation Limited (Puyang, China) in 2016. 
Male New Zealand rabbits, 2-3 kg, fed with adequate food and water for 12 weeks (temperature $20 \pm 5{ }^{\circ} \mathrm{C}$, humidity $45-65 \%$ ) were used. Breviscapine was purchased from Yunnan Bio Valley Pharmaceutical Co., Ltd., Kunming 650503, China. Enzyme-linked immunosorbent assay (ELISA) kits of prothrombin time (PT, 20180502), activated partial thromboplastin time (APTT, 20180515T), and thrombin time (TT, 20180416) were all purchased from Shenzhen Dulei Biological science Co., Ltd., Shenzhen 518067, China. All other materials were purchased with the grade of the corresponding methods.

\subsection{Extraction and Purification of Polysaccharides from F. Velutipes}

The polysaccharides of $F$. velutipes were extracted and purified by the modified method of Zhang [11] and Wang [12]. During the method, lipids, pigments, and small molecular compounds were all washed out from $F$. velutipes firstly. Then, the residue was extracted with distilled water three times. The supernatant was filtered, combined, and concentrated. After that, the crude polysaccharides were precipitated by adding ethanol and washed successively with anhydrous ethanol, acetone, and petroleum ether. Then, Sevag reagent and dialysis bags were used to deproteinize the crude polysaccharides and remove some salts. Finally, crude F. velutipes polysaccharides (FVP) were obtained after the freeze-dried processing.

First, we dissolved the crude FVP in distilled water and separated it into fractions by a Diethylaminoethyl cellulose-52 column (DEAE-52 cellulose column). Then, the fractions were eluted by solvent gradient chromatography with $0,0.05,0.1,0.2$, and $0.5 \mathrm{M} \mathrm{NaCl}$ $(1.3 \mathrm{~mL} / \mathrm{min})$. The phenol-sulfuric acid method was used to monitor the factions of crude FVP, and some completely separated fractions were collected. After dialysis, concentration, and purification with a Sephadex G-100 column, two main fractions, CHFVP-1 and CHFVP2 , were obtained.

\subsection{Ultraviolet Spectrum Scan}

CHFVP-1 and CHFVP-2 solutions $(1 \mathrm{mg} / \mathrm{mL})$ were analyzed by UV spectroscopy at a wavelengths range of $200-800 \mathrm{~nm}$ [13].

\subsection{Infrared Spectrum Analysis}

The infrared spectrum of CHFVP-1 and CHFVP-2 was measured by a Fourier-transform infrared (FT-IR) spectrometer with the KBr pellet method in the range of 4000-400 $\mathrm{cm}^{-1}$.

\subsection{Molecular Weight Determination Analysis}

The relative molecular weight of CHFVP-1 and CHFVP-2 were commissioned for Beijing Physical and Chemical Analysis and Testing Center and determined according to the 2015 edition of the Pharmacopoeia of the People's Republic of China.

\subsection{Monosaccharide Composition Analysis}

Gas chromatography (GC) in reference [12], a popular method for monosaccharide composition, was adopted in this paper. Briefly, hydrolyze sample with trifluoroacetic acid (TFA) and get the hydrolysates. Mix it with hydroxylamine hydrochloride, inositol hexyl acetate, and pyridine, add acetic anhydride, and bathe the mixture in hot water for $40 \mathrm{~min}$. After that, dissolve it in chloroform. Filter the reactants and analyze it by gas chromatography fitted with a Thermo TG-Waxms capillary column $(30 \mathrm{~m} \times 0.32 \mathrm{~mm} \times 0.5 \mu \mathrm{m})$. The analysis situation of GC was the same as Wang's research [12]. The related monosaccharide (glucose, arabinose, xylose, ribose, fucose, mannose, fructose, galactose, and rhamnose) was derived with the above method.

\subsection{Methylation Analysis}

In this part, the analysis of CHFVP-1 and CHFVP-2 was consistent with the method of Ciucanu et al. [14]. Briefly, dissolve the sample in the dimethyl sulfoxide (DMSO); then, add $\mathrm{NaOH}$ dry powder and $\mathrm{CH}_{3} \mathrm{I}$ to methylate it. During this step, the absorption 
(3200-3700 $\mathrm{cm}^{-1}$ ) on infrared spectroscopy was used to judge the success of methylation. The sample after methylation was hydrolyzed at $100{ }^{\circ} \mathrm{C}$ by adding Trifluoroacetic Acid (TFA). After cooling, $\mathrm{NaOH}$ solution and $\mathrm{NaBH}_{4}$ were added to the sample for reaction, and next, acetic acid was used to neutralize the sample. Then, we added pyridine and acetic anhydride for acetylation before analysis with the GC-Mass Spectrophotometer (MS) system with a J\&W DB-5 ms capillary column $(30 \mathrm{~m} \times 250 \mu \mathrm{m} \times 0.25 \mu \mathrm{m})$. The GC situation was that the temperature increased from 110 to $190{ }^{\circ} \mathrm{C}$ at the rate of $5{ }^{\circ} \mathrm{C} / \mathrm{min}$, to $210{ }^{\circ} \mathrm{C}$ at $3{ }^{\circ} \mathrm{C} / \mathrm{min}$ and finally to $230{ }^{\circ} \mathrm{C}$ at $5{ }^{\circ} \mathrm{C} / \mathrm{min}$.

\subsection{Nuclear Magnetic Resonance (NMR) Spectroscopy}

Dissolve $15 \mathrm{mg}$ of CHFVP- 1 and CHFVP- 2 in $0.5 \mathrm{~mL}$ of $\mathrm{D}_{2} \mathrm{O}$ (the internal standard was Tetramethylsilane, TMS), respectively and load them into the NMR tube. NMR experiments were recorded on a Bruker-AV-500 spectrometer at $25^{\circ} \mathrm{C}$. The measured spectra included ${ }^{1} \mathrm{H},{ }^{13} \mathrm{C}, \mathrm{H} / \mathrm{H}$ correlation spectroscopy (COSY), heteronuclear single quantum coherence spectroscopy (HSQC), and heteronuclear multiple bond correlation spectroscopy (HMBC).

\subsection{Coagulation Activities In Vitro}

CHFVP-1 and CHFVP-2 were separately dissolved in saline, and $5 \mathrm{mg} / \mathrm{mL}$ of sample solutions were obtained. Then, we mixed them together for the next step. Breviscapine were dissolved in saline to get $13.3 \mathrm{mg} / \mathrm{mL}$ solution. The preparation method of Yunnan Baiyao was similar to Breviscapine [15]. Rabbits were used as experimental animals, and then PT, APTT, and TT detection kits were used for determination. Sodium citrate in saline was taken into an eppendorf (EP) tube, rabbit ear venous blood was added, and plasma was prepared after being centrifuged at $3000 \mathrm{~g} / \mathrm{min}$ for $15 \mathrm{~min}$ (TGL-16gR, Shanghai Anting Scientific Instrument Co., Shanghai, China). CHFVP-1 and CHFVP-2 were transferred to plasma, and APTT was added. After preheating and incubating it for $5 \mathrm{~min}$, steel balls and $\mathrm{CaCl}_{2}$ solution were added successively and pre-warmed at $37^{\circ} \mathrm{C}$. Finally, the experimental results were recorded. For PT analysis, CHFVP-1 and CHFVP-2 and serum were incubated with the coagulation and minimum steel ball cell at $37^{\circ} \mathrm{C}$ for $3 \mathrm{~min}$. After that, PT reagent was added at $37^{\circ} \mathrm{C}$. TT analysis was determined according to the instruction. During the determination, according to many researchers, breviscapine and Yunnan Baiyao were taken as anti-coagulated [16] and pro-coagulated [17] reagents, respectively, while the normal saline was taken in the blank control group. Record the thrombus time with the RAC-030 automatic coagulation analyzer (Shenzhen Leidu Life Science Co., Ltd., Shenzhen 518067, China). The software SPSS 22.0 was used for data analysis.

\section{Results and Discussion}

\subsection{Preparation of Polysaccharides from $F$. Velutipes}

After the extraction of polysaccharides from $F$. velutipes, the crude polysaccharides were obtained, and the yield was about $1.33 \%$ (on dry; g/g). After the DEAE-52 cellulose column isolation, FVP was separated into five components (Figure 1a). In this study, FVP-1 and FVP-2 were selected for the next step of purification and structural study. Then, the purified yields of FVP- 1 and FVP-2 were $8.4 \%$ and $36.2 \%$ respectively and purified with the Sephadex G-100 column to obtain the pure subfraction CHFVP-1 (Figure 1b) and CHFVP-2 (Figure 1c) with a yield of $88.4 \%$ and $78.9 \%$ (by dry weight).

\subsection{Spectroscopic Characteristics}

The sample of FVP, CHFVP-1, and CHFVP-2 were scanned through ultraviolet spectrum, and the characterization of their absorption spectrum is shown in Figure 2. It could be found that there was no ultraviolet absorption at 260 and $280 \mathrm{~nm}$, which means that FVP, CHFVP-1, and CHFVP-2 did not contain free protein and nucleic acid. 


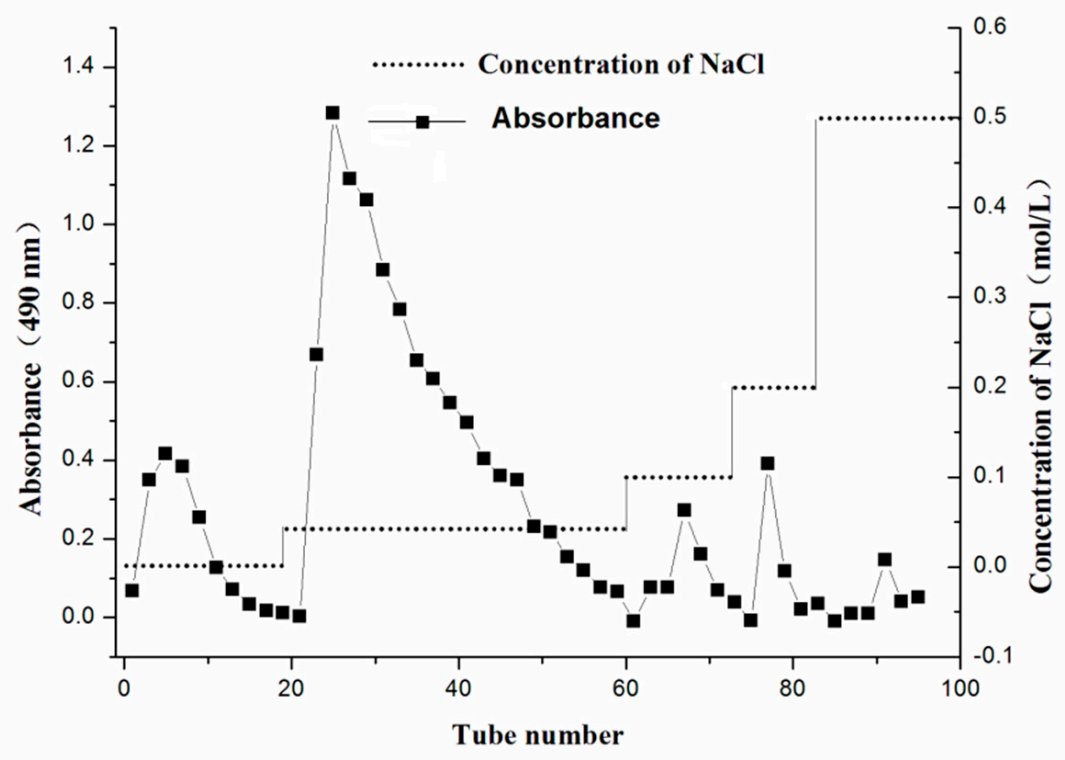

(a)

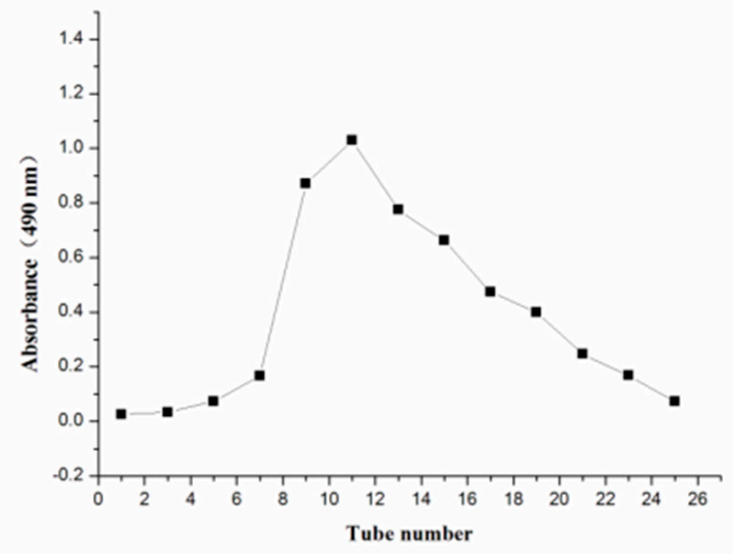

(b)

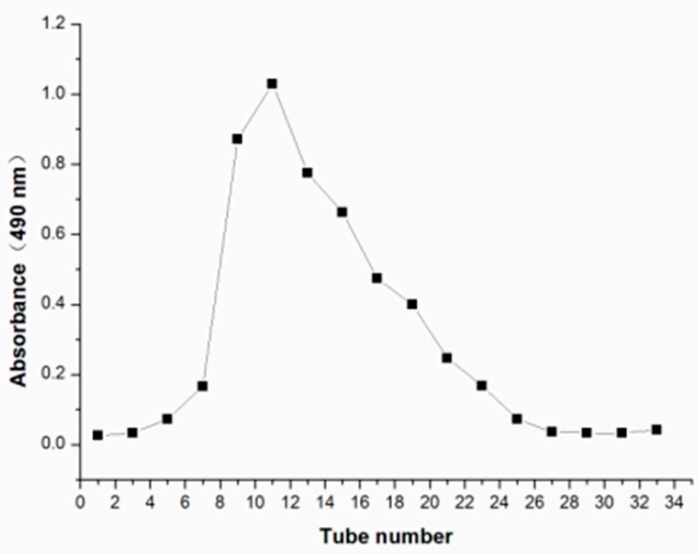

(c)

Figure 1. Isolation and purification of crude polysaccharide from F. velutipes. (a) The elution curve of F. velutipes polysaccharides (FVP); (b) The elution curve of FVP-1; (c) The elution curve of FVP-2. 


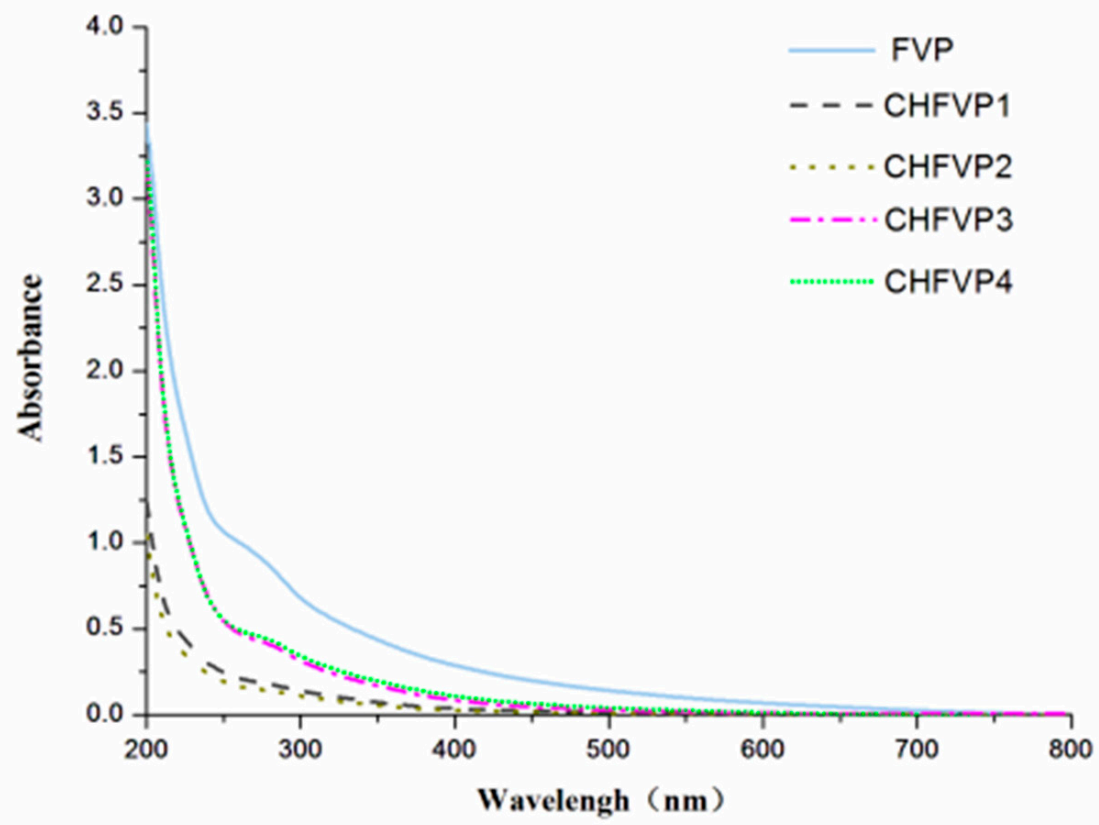

Figure 2. Wavelength scanning curve of CHFVP-1, CHFVP-2, CHFVP-3, CHFVP-4, and FVP.

The infrared spectra of CHFVP-1 and CHFVP-2 at the range of $400-4000 \mathrm{~cm}^{-1}$ were scanned and are shown in Figure 3. The two fractions revealed the hydroxyl group (-OH) for the broad and strong absorption peak at around $3400 \mathrm{~cm}^{-1}$ [18]. The peaks at 2935 and $2923 \mathrm{~cm}^{-1}$ indicated the $\mathrm{C}, \mathrm{H}$ and aliphatic C-H bonds, respectively [19]. Stretching peaks at 1642 and $1653 \mathrm{~cm}^{-1}$ corresponded to free carboxyl groups [20]. The broad absorption bands with intense intensities around $1420-1300 \mathrm{~cm}^{-1}$ could be owing to stretching vibrations of the C-H bond [21]. The absorption band at $1000-1200 \mathrm{~cm}^{-1}$ suggested that the two polysaccharides contained pyranose monomers in their structures [22]. The absorption bands at 882 and $888 \mathrm{~cm}^{-1}$ indicated the $\beta$-pyranoside linkage in CHFVP- 1 and CHFVP-2 [23].

\subsection{Molecular Weight and Monosaccharides Composition of CHFVP-1 and CHFVP-2}

The average molecular masses of CHFVP-1 and CHFVP-2 were 24.44 and $1497 \mathrm{kDa}$, respectively (Table 1). The GC result of standard monosaccharides is shown in Figure 4a. According to the comparison between Figure $4 a, b$, it was found that CHFVP- 1 was composed of fucose (Fuc), mannose (Man), glucose (Glu), and galactose (Gal) with a molar ratio of 1.51:3.42:15.28:10.00, respectively. CHFVP-2 was composed of arabinose (Ara), xylose (Xyl), ribose (Rib), Man, Glu, and Gal with a molar ratio of 0.85:0.47:0.42:1.79:18.46:1.00 (Figure 4c). Glu contributed to the main part of monosaccharides composition, indicating that glucose might be the main structure unit of CHFVP-1 and CHFVP-2, especially in CHFVP-2.

Table 1. Molecular weight of polysaccharides from F. velutipes.

\begin{tabular}{cccccc}
\hline Polysaccharides & $\mathbf{M n}$ & $\mathbf{M p}$ & $\mathbf{M w}$ & $\mathbf{M z}$ & $\mathbf{M w} / \mathbf{M n}$ \\
\hline CHFVP-1 & 23,440 & 22,460 & 24,440 & 25,850 & 1.042 \\
CHFVP-2 & $1,462,000$ & $1,600,000$ & $1,497,000$ & $1,537,000$ & 1.024 \\
\hline
\end{tabular}

Note: The number average molecular weight $(\mathrm{Mn}, \mathrm{g} / \mathrm{mol})$ is the statistical average molecular weight of all polymeric chains in the polysaccharides; the weight average molecular weight $(\mathrm{Mw}, \mathrm{g} / \mathrm{mol})$ is the statistical average of all molecular weights in the polysaccharides; $\mathrm{Mp}(\mathrm{g} / \mathrm{mol})$ is defined as the molecular weight of the highest peak; $\mathrm{Mz}(\mathrm{g} / \mathrm{mol})$ is defined as Z-average molecular mass, which is calculated according to the precipitation equilibrium method to determine the chain length; the ratio of $\mathrm{Mw} / \mathrm{Mn}$ is called the polydispersity coefficient, which is used to describe the molecular mass distribution of polysaccharides. 


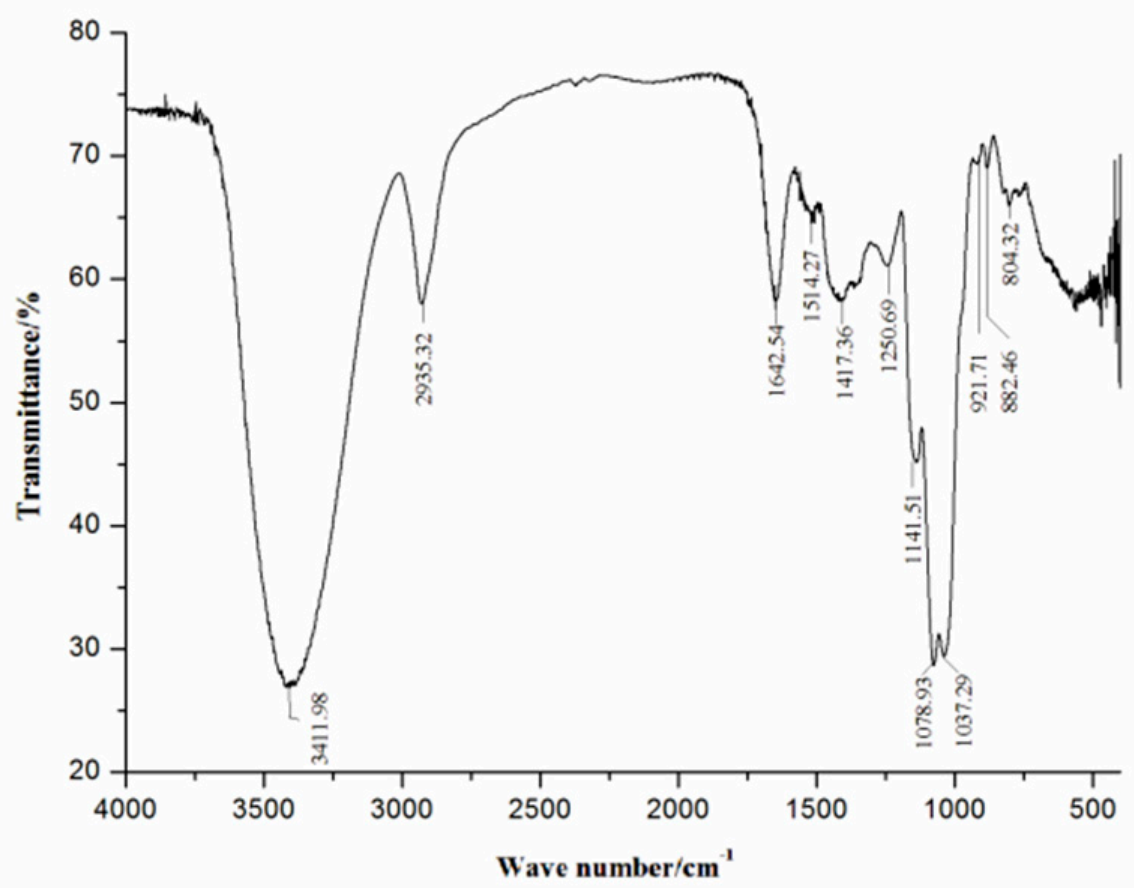

(a)

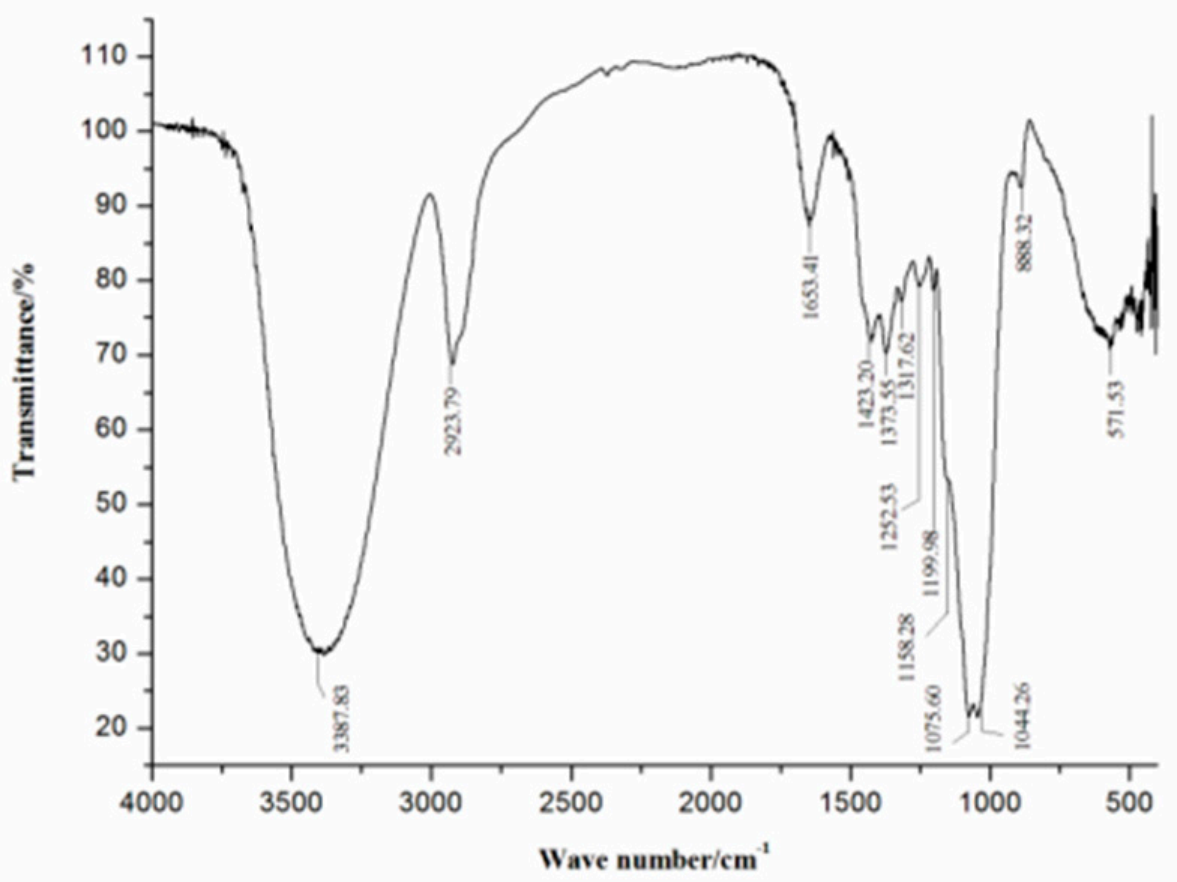

(b)

Figure 3. (a) The Fourier-transform infrared (FT-IR) spectroscopy of CHFVP-1; (b) The FT-IR spectroscopy of CHFVP-2. 


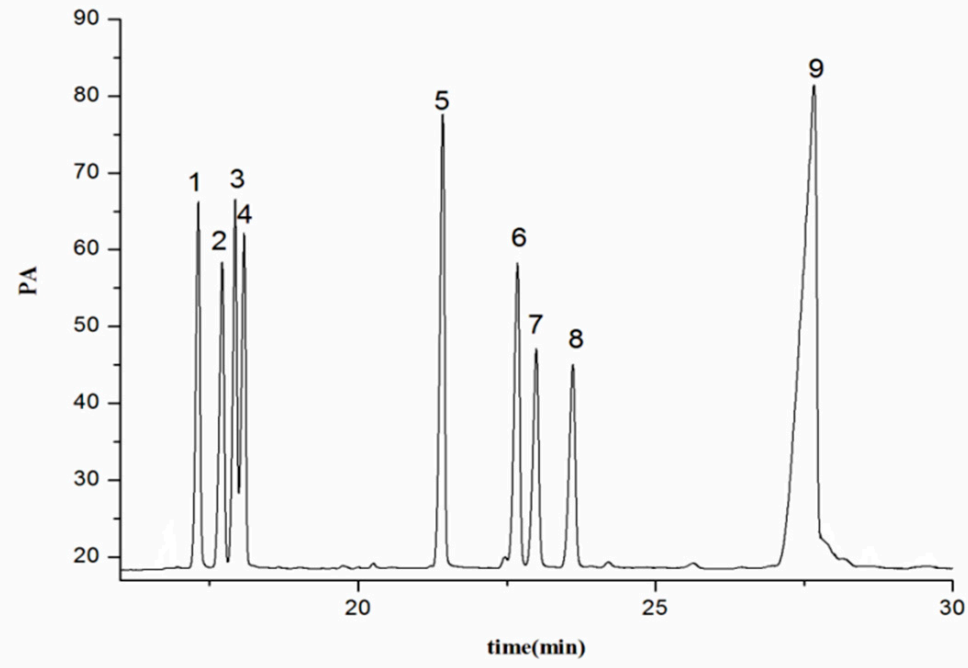

(a)

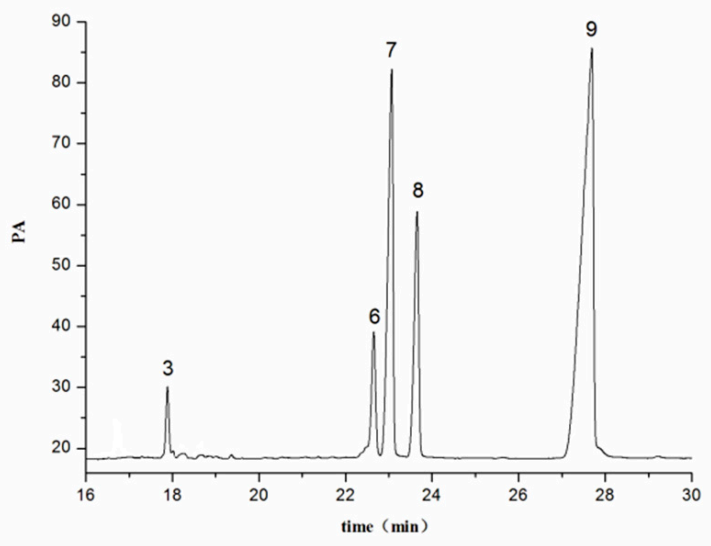

(b)

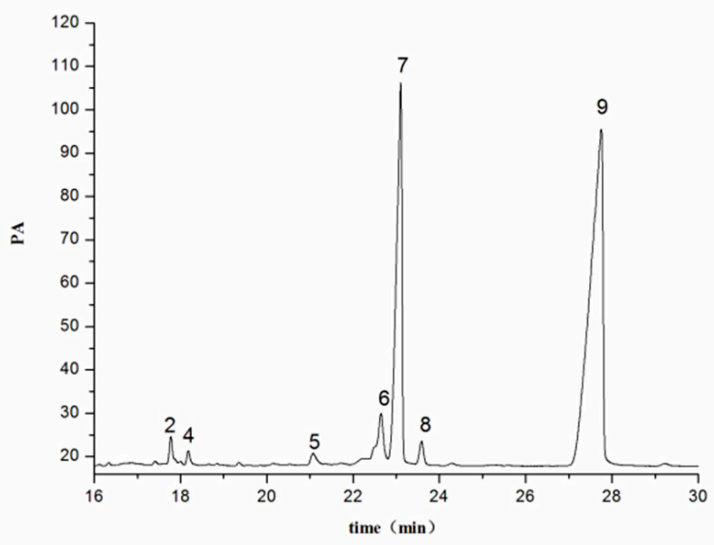

(c)

Figure 4. The monosaccharide composition results of (a) reference; (b) CHFVP-1 and (c) CHFVP-2. (1: Rha; 2: Ara; 3: Fuc; 4: Xyl; 5: Ribose; 6: Man; 7: Glc; 8: Gal; 9: internal standard). 


\subsection{Methylation Analysis of CHFVP-1 and CHFVP-2}

The glycosidic linkage and relative percentage of each sugar residue derivative according to the gas chromatography peak area determination from CHFVP-1 and CHFVP-2 were performed by methylation analysis (Table 2). The highest proportion of the sugar residue was the 1,6-Linked-Gal (33.25\%) in CHFVP-1, followed by T-Glc (28.23\%), 1,6-Linked-Glc (19.00\%), 1,3,6-Linked-Man (10.18\%), and 1,2,6-Linked-Man (9.24\%). The residue related to the glucose, including 1, 6-Linked-Glc and T-Glc, accounted for almost half of all sugar residues. The results showed that glucose is composed of the main chain of CHFVP-1.

Table 2. GC-MS date for methylation analysis of CHFVP-1.

\begin{tabular}{|c|c|c|c|}
\hline Retention Time (min) & PMAA & Linkages Types & Percentage $(\%)$ \\
\hline 20.26 & 2,3,4,6-Me ${ }_{4}$-Glc & T-Glc & 28.23 \\
\hline 22.33 & 2,4-Me 2 -Man & 1,3,6-Linked-Man & 10.18 \\
\hline 23.13 & $2,3,4-\mathrm{Me}_{3}-\mathrm{Glc}$ & 1,6-Linked-Glc & 19.00 \\
\hline 24.14 & $2,3,4-\mathrm{Me}_{3}-\mathrm{Gal}$ & 1,6-Linked-Gal & 33.25 \\
\hline 26.07 & 3,4-Me $-\mathrm{Me}_{2} \mathrm{Man}$ & 1,2,6-Linked-Man & 9.24 \\
\hline
\end{tabular}

According to the results in Table 3 , it could be found that CHFVP-2 is a glucan with T-Glc (67.01\%) and 1,6-Linked-Glc (32.99\%).

Table 3. GC-MS date for methylation analysis of CHFVP-2.

\begin{tabular}{cccc}
\hline $\begin{array}{c}\text { Retention Time } \\
(\text { min) }\end{array}$ & PMAA & Linkages Types & Percentage (\%) \\
\hline 20.28 & $2,3,4,6-\mathrm{Me}_{4}$-Glc & T-Glc & 67.01 \\
23.15 & $2,3,4-\mathrm{Me}_{3}$-Glc & 1,6-Linked-Glc & 32.99 \\
\hline
\end{tabular}

Note: PMAA is the sugar alcohol acetate derivatives.

\subsection{NMR Analysis of CHFVP-1 and CHFVP-2}

The NMR spectra of CHFVP-1 are shown in Figure 5, which were the basis for inferring monosaccharide, glycosidic linkages, and chemical shifts. In Figure $5 \mathrm{a}, \mathrm{b}$, most of the proton and carbon chemical shifts of CHFVP-1 come from the regions ranging from $\delta 3.0$ to 5.50 and $\delta 60$ to 110 , respectively, which were the typical chemical shifts of the polysaccharide [24]. Furthermore, four anomeric proton and carbon chemical shifts at $\delta$ $4.53 / 106.29, \delta 5.001 / 100.79, \delta 5.11 / 105.25$, and $\delta 5.06 / 104.44$ were identified in the ${ }^{1} \mathrm{H}$ NMR, ${ }^{13} \mathrm{C}$ NMR, and HSQC in Figure 5 and indicated as A, B, C, and D in CHFVP-1.

According to the composition of monosaccharides, methylation results, and literature comparison, the carbon signals at $\delta 18.52$ in the ${ }^{13} \mathrm{C}$ NMR and the proton shift at $\delta 1.23$ in the ${ }^{1} \mathrm{H}$ NMR indicated the existence of terminal-fucose (T-fuc) in CHFVP-1 $[25,26]$. The peak at $\delta 105.25$ indicated the presence of ${ }^{13} \mathrm{C}$ of $\alpha-1,3,6$-linked D-mannopyranose units [27-29]. The peak at $\delta 100.79$ meant the existence of C1 of the $\alpha$-D-galactose [30]. The signal peak appearing at $\delta 64.0$ suggested the presence of the C-6 galactose in the polysaccharide sugar chain structure [31]. The peaks in the region of $\delta 63.83-80.37$ indicated the typical shift of carbohydrate. The glycosidic linkage of CHFVP-1 determined by its ${ }^{1} \mathrm{H}$ NMR spectra in the region of $\delta 4.53-5.11$ revealed that there were both $\alpha$ - and $\beta$-configurations in it [32].

According to the anomeric chemical shift at $\delta 4.53 / 106.29$ and literature comparison, the $\beta$-configuration of residue $A$ was determined [33]. From the COSY spectrum (Figure 5c), the chemical shifts of $\mathrm{H} 2-\mathrm{H} 6$ can be deduced to $\delta 3.47, \delta 3.72, \delta 3.96, \delta 4.36$, and $\delta 3.76$, respectively. The ${ }^{13} \mathrm{C}$ chemical shifts of residue A were obtained from the HSQC spectrum by the chemical shift of ${ }^{1} \mathrm{H}$ (Figure $5 \mathrm{~d}$ ), and the results are summarized in Table 4 . Furthermore, according to the related literature and the chemical shifts of all ${ }^{1} \mathrm{H}$ and ${ }^{13} \mathrm{C}$ of residue A $[25,34]$, residue A should be terminal- $\beta$-D-Glc $p$. 


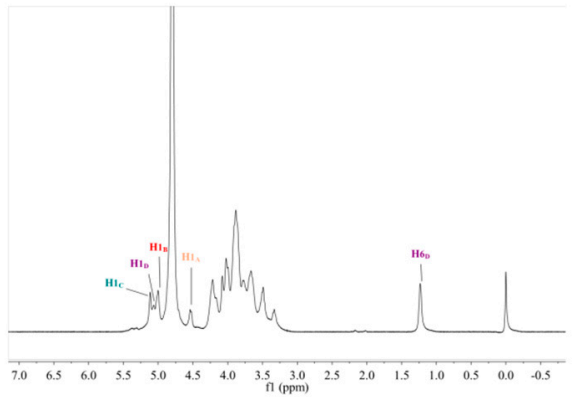

(a)
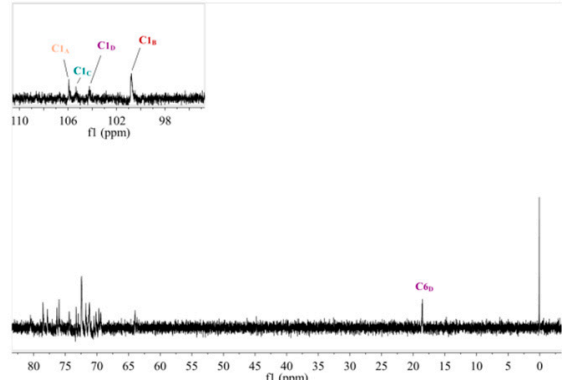

(b)

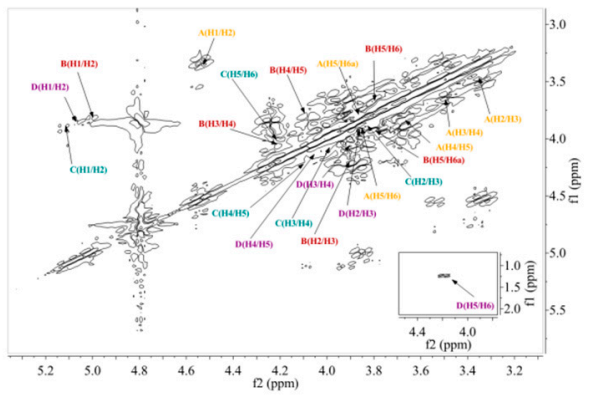

(c)

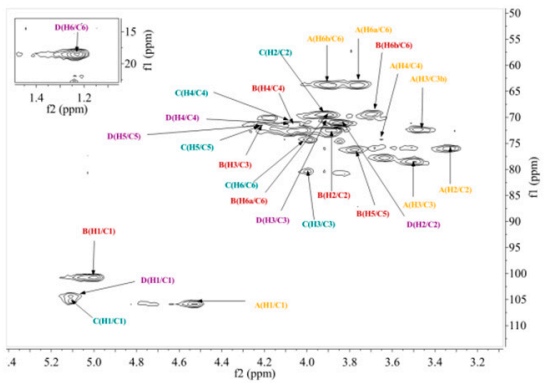

(d)

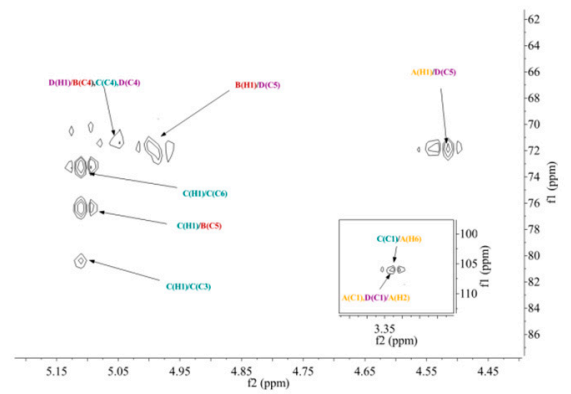

(e)

Figure 5. ${ }^{1} \mathrm{H}$ spectrum (a); ${ }^{13} \mathrm{C}$ spectrum (b); COSY spectrum (c); HSQC spectrum (d); HMBC spectrum (e). 
Table 4. ${ }^{1} \mathrm{H}$ and ${ }^{13} \mathrm{C}$ NMR chemical shifts of CHFVP-1 fraction recorded in $\mathrm{D}_{2} \mathrm{O}$ at $291 \mathrm{~K}$.

\begin{tabular}{|c|c|c|c|c|c|c|c|}
\hline \multirow{2}{*}{ Glycosyl Residue } & & \multicolumn{6}{|c|}{ Chemical Shift $\delta \mathrm{H} / \mathrm{C}$ (ppm) } \\
\hline & & H1/C1 & $\mathrm{H} 2 / \mathrm{C} 2$ & H3/C3b & H4/C4 & H5/C5 & $\mathrm{H6a} / \mathrm{C6}$ \\
\hline $\mathrm{A}$ & $\mathrm{H}$ & 4.53 & 3.35 & 3.49 & 3.66 & 3.86 & $3.77 / 3.90$ \\
\hline T- $\beta$-D-Glc $p$ & $\mathrm{C}$ & 106.29 & 75.97 & $78.78 / 72.3$ & 72.83 & 71.08 & 63.832 \\
\hline B & $\mathrm{H}$ & 5.00 & 3.89 & 4.21 & 4.07 & 3.79 & $3.91 / 3.70$ \\
\hline$\rightarrow 6)-\alpha$-D-Gal $p-(1 \rightarrow$ & $\mathrm{C}$ & 100.79 & 72.43 & 71.56 & 71.21 & 76.21 & 69.45 \\
\hline C & $\mathrm{H}$ & 5.11 & 3. 91 & 3.99 & 4.07 & 4.22 & 4.00 \\
\hline$\rightarrow 3,6)-\alpha-\mathrm{D}-\mathrm{Man} p-(1 \rightarrow$ & $\mathrm{C}$ & 105.25 & 69.75 & 80.37 & 71.21 & 71.61 & 74.25 \\
\hline D & $\mathrm{H}$ & 5.06 & 3.86 & 3.91 & 4.074 & 4.17 & 1.23 \\
\hline T- $\alpha-\mathrm{L}-\mathrm{Fuc} p$ & $\mathrm{C}$ & 104.44 & 71.35 & 71.56 & 71.21 & 71.77 & 18.52 \\
\hline
\end{tabular}

According to the anomeric chemical shift at $\delta 5.00 / 100.79$ and literature comparison, the $\alpha$-configuration of residue B was determined. The other chemical shifts of $\mathrm{H}-2, \mathrm{H}-3$, $\mathrm{H}-4, \mathrm{H}-5, \mathrm{H}-6$ and H-6a at $\delta 3.89, \delta 4.21, \delta 4.07, \delta 3.79, \delta 3.91$ and $\delta 3.70$ were found from the cross-peaks in the COSY spectra (Figure $5 \mathrm{c}$ ), and the corresponding carbon signals could be attributed to the correlations of C-H signals in the HSQC spectrum (Figure $5 \mathrm{~d}$ ), which were $\delta 72.43, \delta 71.56, \delta 71.21, \delta 76.21$, and $\delta 69.45$ for C-2, C-3, C-4, C-5, and C-6, respectively. Regarding the complete ${ }^{1} \mathrm{H}$ and ${ }^{13} \mathrm{C}$ chemical shifts of residue $\mathrm{B}$ as well as previous work [35], residue B was $\rightarrow 6)-\alpha$-D-Gal $p-(1 \rightarrow$.

The heterotopic hydrogen and carbon signals of $\mathrm{H}-1$ and C-1 were $\delta 5.11 / 105.25$. According to the literature, residue $C$ was inferred to be an $\alpha$-configuration residue. Other signals from $\mathrm{H}-2$ to $\mathrm{H}-6 \mathrm{a}$ were identified from the results of COSY spectrum (Figure $5 \mathrm{c}$ ),

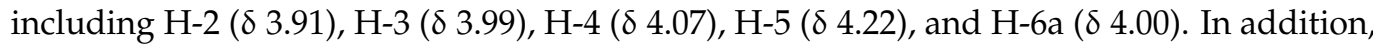
the matching ${ }^{13} \mathrm{C}$ chemical shifts were $\mathrm{C}-2(\delta 69.75), \mathrm{C}-3(\delta 80.37), \mathrm{C}-4(\delta 71.21), \mathrm{C}-5(\delta 71.61)$, and C-6 $(\delta 74.25)$ in the HSQC spectrum (Figure $5 \mathrm{~d}$ ). The chemical shifts of all ${ }^{1} \mathrm{H}$ and ${ }^{13} \mathrm{C}$ of residue $C$ were basically consistent with the literature [29], which indicated that residue C was $\rightarrow 3,6)-\alpha$-D-Man $p-(1 \rightarrow$.

Based on the terminal ${ }^{13} \mathrm{C}$ and ${ }^{1} \mathrm{H}$ shift at $\delta 5.06 / 104.44$, the $\alpha$-configuration of the $\mathrm{D}$ residue was inferred. In the HSQC spectrum (Figure $5 \mathrm{~d}$ ), the cross-peak at $81.23 / 18.525$ indicated the H6/C6 of T- $\alpha$-L-Fucp. The remaining hydrogen chemical shifts of D come from the COSY (Figure 5c) spectrum, and the ${ }^{13} \mathrm{C}$ chemical shifts associated with it were determined in the HSQC spectrum (Figure $5 \mathrm{~d}$ ). Compared with the literature, the ${ }^{1} \mathrm{H}$ and ${ }^{13} \mathrm{C}$ chemical shifts for residue D were assigned [26]. The NMR chemical shifts and significant connectivity are summarized in Tables 4 and 5.

Table 5. Significant connectivity observed in $\mathrm{HMBC}$ spectrum for the terminal ${ }^{1} \mathrm{H}$ and ${ }^{13} \mathrm{C}$ of the residue fractions of CHFVP-1.

\begin{tabular}{|c|c|c|c|c|c|}
\hline \multirow{2}{*}{ Sugar Residue } & \multirow{2}{*}{ Sugar Linkage } & \multicolumn{4}{|c|}{ H-1/C-1 (ppm) Connectivities } \\
\hline & & $\delta_{\mathrm{H}} / \delta_{\mathrm{C}}$ & $\delta_{\mathrm{H}} / \delta_{\mathrm{C}}$ & Residue & Atom \\
\hline \multirow[t]{2}{*}{ A } & $\mathrm{T}-\beta-\mathrm{D}-\mathrm{Glc} p$ & 4.53 & 71.77 & $\mathrm{D}$ & C-5 \\
\hline & & 106.29 & 3.35 & A & $\mathrm{H}-2$ \\
\hline \multirow[t]{2}{*}{$\mathrm{B}$} & $\rightarrow 6)-\alpha-\mathrm{D}-\mathrm{Gal} p-(1 \rightarrow$ & 5.001 & 71.77 & $\mathrm{D}$ & $C-5$ \\
\hline & & 100.79 & & & \\
\hline \multirow[t]{4}{*}{$\mathrm{C}$} & $\rightarrow 3,6)-\alpha-\mathrm{D}-\mathrm{Man} p-(1 \rightarrow$ & 5.11 & 74.25 & $\mathrm{C}$ & C-6 \\
\hline & & & 76.21 & $\mathrm{~B}$ & C-5 \\
\hline & & & 80.37 & $\mathrm{C}$ & $C-3$ \\
\hline & & 105.25 & 3.37 & A & H-6 \\
\hline \multirow[t]{2}{*}{$\mathrm{D}$} & T- $\alpha-\mathrm{L}-\mathrm{Fuc} p$ & 5.06 & 71.21 & $\mathrm{~B} / \mathrm{C} / \mathrm{D}$ & C-4 \\
\hline & & 104.44 & 3.35 & A & $\mathrm{H}-2$ \\
\hline
\end{tabular}

Due to the large molecular weight and viscosity of CHFVP-1 and the wide distribution of branched chains, the NMR data of the sample were incomplete, and only partial sugar 
residue fragments were inferred. According to the correlation between the peaks of ${ }^{13} \mathrm{C}$ and ${ }^{1} \mathrm{H}$ from the HMBC spectrum (Figure 5e), the glycosides of the CHFVP-1 residues were linked as follows: AC-1/AH-2; AH-1/DC5; BH-1/DC-5; CC-1/AH-6; CH-1/BC5/CC-6/3; DH-1/B/C/DC-4; DC-1/AH-2. Hence, considering the aforementioned results, the most probable repeat unit of CHFVP-1 has an $\rightarrow 6)-\alpha$-D-Galp- $(1 \rightarrow$ backbone that is branched at O- 5 of Gal $p$ by an $\rightarrow 3,6)-\alpha$-D-Man $p$-( $1 \rightarrow$ attached with T- $\beta$-D-Glc $p$ or T- $\alpha$-LFuc $p$ side-chains.

CHFVP-2 was analyzed by the same way as that used for CHFVP-1. In Figure 6, anomeric proton and carbon signals at $\delta 4.53 / 105.88$ were determined in the ${ }^{1} \mathrm{H}$ and ${ }^{13} \mathrm{C}$ NMR (Tables 6 and 7) and HSQC spectra in Figure 6 and denoted as A and B in CHFVP-2 [34]. All the ${ }^{1} \mathrm{H}$ and ${ }^{13} \mathrm{C}$ signals were assigned by ${ }^{1} \mathrm{H} /{ }^{1} \mathrm{H}$ correlation spectroscopy (COSY), heteronuclear single quantum coherence (HSQC), and heteronuclear multiplebond correlation (HMBC), as shown in Figure 6, indicating that residue A was T- $\beta$-D-Glc $p$ and $\mathrm{B}$ was $\rightarrow 6)-\beta$-D-Glc $p-(1 \rightarrow$.

Table 6. ${ }^{1} \mathrm{H}$ and ${ }^{13} \mathrm{C}$ NMR chemical shifts of CHFVP-2 fraction recorded in $\mathrm{D}_{2} \mathrm{O}$ at $291 \mathrm{~K}$.

\begin{tabular}{cccccccc}
\hline \multirow{2}{*}{ Glycosyl Residue } & & \multicolumn{5}{c}{ Chemical Shift $\delta$ H/C (ppm) } \\
\cline { 3 - 8 } & & H1/C1 & H2/C2 & H3/C3b & H4/C4 & H5/C5 & H6/C6b \\
\hline A & H & 4.53 & 3.35 & 3.52 & 3.77 & 3.89 & 3.67 \\
T- $\beta$-D-Glcp & C & 105.88 & 75.93 & 72.38 & 71.71 & 77.78 & $78.44 / 63.58$ \\
B & H & 4.53 & 3.35 & 3.52 & 3.77 & 3.89 & 4.23 \\
$\rightarrow 6$ )- $\beta$-D- Glcp- $(1 \rightarrow$ & C & 105.88 & 75.93 & 72.38 & 71.71 & 77.78 & 71.71 \\
\hline
\end{tabular}

Table 7. Significant connectivity observed in $\mathrm{HMBC}$ spectrum for the terminal ${ }^{1} \mathrm{H}$ and ${ }^{13} \mathrm{C}$ of the residue fractions of CHFVP-2.

\begin{tabular}{|c|c|c|c|c|c|}
\hline \multirow{2}{*}{ Sugar Residue } & \multirow{2}{*}{ Sugar Linkage } & \multicolumn{4}{|c|}{ H-1/C-1 (ppm) Connectivities } \\
\hline & & $\delta_{\mathrm{H}} / \delta_{\mathrm{C}}$ & $\delta_{\mathrm{H}} / \delta_{\mathrm{C}}$ & Residue & Atom \\
\hline \multirow[t]{4}{*}{ A } & T- $\beta$-D-Glc $p$ & 4.53 & 71.71 & B & C-6 \\
\hline & & & & $\mathrm{A} / \mathrm{B}$ & $C-4$ \\
\hline & & 105.88 & 3.89 & $\mathrm{~A} / \mathrm{B}$ & $\mathrm{H}-5$ \\
\hline & & & 3.35 & $\mathrm{~A} / \mathrm{B}$ & $\mathrm{H}-2$ \\
\hline \multirow[t]{4}{*}{ B } & $\rightarrow 6)-\beta$-D- Glcp-(1 $\rightarrow$ & 4.53 & 71.71 & B & C-6 \\
\hline & & & & $\mathrm{A} / \mathrm{B}$ & C-4 \\
\hline & & 105.88 & 3.89 & $\mathrm{~A} / \mathrm{B}$ & H-5 \\
\hline & & & 3.35 & $\mathrm{~A} / \mathrm{B}$ & $\mathrm{H}-2$ \\
\hline
\end{tabular}

The structure of CHFVP-2 was proposed based on the above analysis in the same way used for CHFVP-1, and the possible partial structure of CHFVP-2 information was shown as follows:

$$
\begin{array}{ccc} 
& \rightarrow \text { [6)- } \beta \text {-D-Glc } p \text { - }(1 \rightarrow 6)-\beta \text {-D-Glc } p-(1 \rightarrow 6)-\beta \text {-D-Glc } p \text { - }(1]_{\mathrm{n}} \rightarrow & \\
2 & 4 & 5 \\
\uparrow & \uparrow & \uparrow \\
1 & 1 & 1 \\
\beta \text {-D-Glc } p & \beta \text {-D-Glc } p & \beta \text {-D-Glc } p
\end{array}
$$




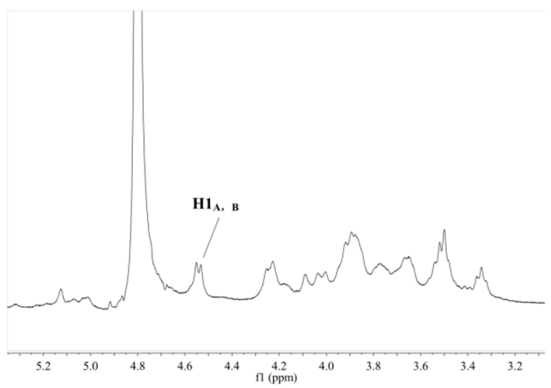

(a)
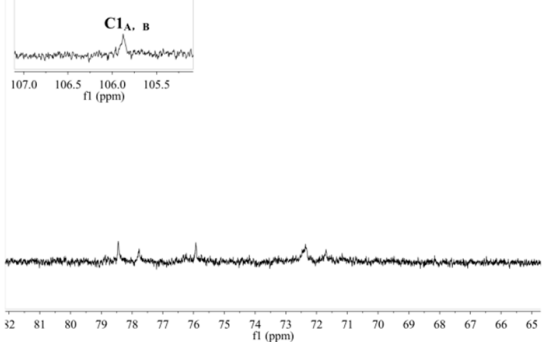

(b)

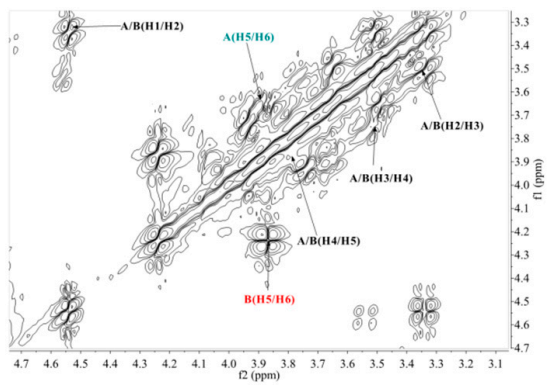

(c)

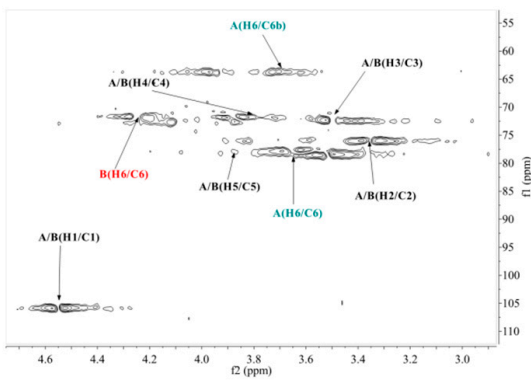

(d)

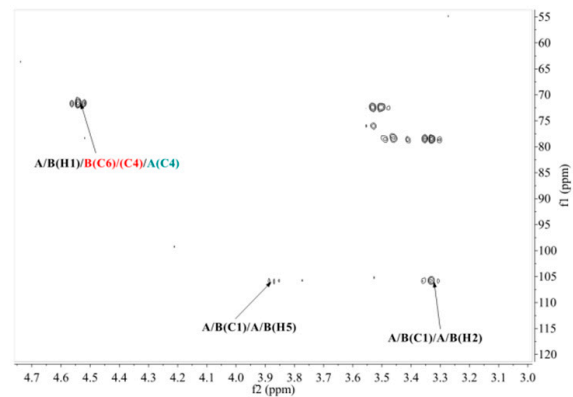

(e)

Figure 6. ${ }^{1} \mathrm{H}$ spectrum (a); ${ }^{13} \mathrm{C}$ spectrum (b); COSY spectrum (c); HSQC spectrum (d); HMBC spectrum (e). 


\subsection{Effects of CHFVP-1 and CHFVP-2 on Parameter Coagulation Parameters In Vitro}

Four kinds of coagulation kits were used to detect the coagulation activity of polysaccharide components, including APTT, PT, and TT in vitro.

In Table 8, CHFVP-2 prolonged PT significantly compared with both the blank group $(p<0.001)$ and breviscapine group $(p<0.01)$, which revealed the extremely significant anticoagulant activity of CHFVP-2. The PT of CHFVP-1 had a slight change but no significant difference. Compared with the blank group, CHFVP-1 significantly shortened APTT, meaning its significant procoagulant activity $(p<0.001)$. CHFVP-2 also had significant procoagulant activity in terms of APTT $(p<0.01)$, and the activity was stronger than that of Yunnan Baiyao. Regarding the effect of TT, CHFVP-1 significantly shortened the TT compared with the blank group, $(p<0.01)$ which had very significant procoagulant activity, while CHFVP-2 also had certain activity.

Table 8. Coagulation effects of CHFVP-1 and CHFVP-2 in vitro.

\begin{tabular}{cccc}
\hline Group & PT(s) & APTT(s) & TT(s) \\
\hline Control & $13.77 \pm 0.30$ & $15.37 \pm 0.15$ & $13.97 \pm 0.23$ \\
Yunnan Baiyao & $12.20 \pm 0.15^{* * *}$ & $14.47 \pm 0.35^{*}$ & $12.57 \pm 0.11^{* * *}$ \\
Breviscapine & $14.77 \pm 0.55^{* *}$ & $16.50 \pm 0.36^{* *}$ & $16.20 \pm 0.53^{* * *}$ \\
CHFVP-1 & $13.57 \pm 0.05^{\# \# \# \& \&}$ & $9.60 \pm 0.42^{* * \# \# \# \& \&}$ & $13.07 \pm 0.30^{* * \& \& \&}$ \\
CHFVP-2 & $15.77 \pm 0.32^{* * \# \# \# \&}$ & $13.95 \pm 0.78^{* * \& \& \&}$ & $13.17 \pm 0.49^{* \# \& \& \&}$
\end{tabular}

Compared with Control, ${ }^{* * *} p<0.001,{ }^{* *} p<0.01,{ }^{*} p<0.05$. Compared with Yunnan Baiyao, ${ }^{\# \# \#} p<0.001,{ }^{\#} p<0.05$. Compared with breviscapine, \&\&\& $p<0.001$, \&\& $p<0.01$.

Based on the above results, CHFVP-1 significantly shortened APTT and TT $(p<0.01)$. Thus, CHFVP-1 could activate coagulation factors and promote the condensing of fibrinogen into insoluble fibrin, indicating that CHFVP-1 promoted blood clotting through the endogenous coagulation pathway. CHFVP-2 shortened APTT but increased PT. It is temporarily unable to predict its coagulation activity in vitro.

\section{Conclusions}

This study isolated two polysaccharides in F. velutipes, CHFVP-1 (24.44 kDa) and CHFVP-2 (1497 kDa), and identified the structural characterization and coagulation activity of them. The CHFVP- 1 was constructed with $\rightarrow 6)-\alpha$-D-Galp-( $1 \rightarrow$ residues as backbone, while CHFVP-2 was constructed with $\rightarrow 6)-\beta$-D-Gal $p-(1 \rightarrow$ residues. Moreover, the branch chain of CHFVP-1 might be inferred as $\rightarrow 3,6)-\alpha$-D-Man $p-(1 \rightarrow$ attached with T- $\beta$-D-Glc $p$ or $\mathrm{t}-\alpha-\mathrm{L}-\mathrm{Fuc} p$, and that of CHFVP-2 was T- $\beta$-D-Glc $p$. Based on the coagulation assay results of APTT and TT of CHFVP-1, the polysaccharide exerted promote blood clotting primarily through endogenous coagulation pathways.

Author Contributions: Conceptualization, Z.L. and J.W.; Data curation, J.W.; Formal analysis, Z.L. and C.L.; Funding acquisition, J.W., C.M. and W.K.; Investigation, W.S.; Methodology, K.Z.; Project administration, C.M.; Resources, C.M.; Software, Q.Z.; Supervision, W.K.; Validation, W.S. and C.L.; Visualization, Q.Z. and C.M.; Writing-original draft, Z.L., K.Z. and J.W.; Writing-review and editing, W.K. All authors have read and agreed to the published version of the manuscript.

Funding: This research was funded by National Key R\&D Program of China, grant number 2018YFD0400200; Major Public Welfare Projects in Henan Province, grant number 201300110200 and The Key Project in Science and Technology Agency of Henan Province, grant number 212102110019 and 202102110283.

Institutional Review Board Statement: The study was conducted according to the guidelines of the Declaration of Helsinki, and approved by the Ethics Committee of College of Medical, Henan University (HUSOM-2019-035, 2019).

Informed Consent Statement: Not applicable.

Data Availability Statement: All the data used are included in this paper. 
Acknowledgments: We gratefully acknowledge the valuable cooperation of the members of the National R \& D Center for Edible Fungus Processing Technology, Henan University in the experiments.

Conflicts of Interest: The authors declare no conflict of interest.

Ethical Conduct of Research: The study obtained ethical clearance from the Ethics Committee of College of Medical, Henan University (HUSOM-2019-035). The rabbit was treated as the guidelines on the care and use of animals for scientific purposes. All the animal procedures were approved by the Ethical Committee of Henan province, China and conducted in accordance with "Institute ethical committee guidelines" for animal experimentation and care.

\section{References}

1. Xu, H.; Liu, L.Y.; Cao, C.J.; Lu, W.S.; Zhu, Z.H.; Guo, Z.J.; Li, M.; Wang, X.; Huang, D.C.; Wang, S.L.; et al. Would Healing Activity of a Skin Substitude from Residues of Culinary-Medicinal Winter Mushroom Flammulina velutipes (Agaricomycetes) Cultivation. Int.J.Med.Mushrooms. 2019, 21, 683-691. [CrossRef]

2. Zhao, R.Q.; Hu, Q.H.; Ma, G.X.; Su, A.X.; Xie, M.H.; Li, X.F.; Chen, G.T.; Zhao, L.Y. Effects of Flammulina velutipes polysaccharide on immune response and intestinal microbiota in mice. J. Funct. Foods. 2019, 56, 255-264. [CrossRef]

3. Zhao, C.; Zhao, K.; Liu, X.Y.; Huang, Y.F.; Liu, B. In Vitro Antioxidant and Antitumor Activities of Polysaccharides Extracted from the Mycelia of Liquid-Cultured Flammulina velutipes. Food Sci. Technol. Res. 2013, 19, 661-667. [CrossRef]

4. Chen, G.T.; Fu, Y.X.; Yang, W.J.; Hu, Q.H.; Zhao, L.Y. Effects of polysaccharides from the base of Flammulina velutipes stipe on growth of murine RAW264.7, B16F10 and L929 cells. Int. J. Biol. Macromol. 2018, 107, 2150-2156. [CrossRef]

5. Yang, W.J.; Pei, F.; Shi, Y.; Zhao, L.Y.; Fang, Y.; Hu, Q.H. Purification, characterization and anti-proliferation activity of polysaccharides from Flammulina velutipes. Carbohyd. Polym. 2012, 88, 474-480. [CrossRef]

6. Zhang, T.T.; Ye, J.F.; Xue, C.H.; Wang, Y.M.; Liao, W.Z.; Mao, L.M.; Yuan, M.M.; Lian, S. Structural characteristics and bioactive properties of a novel polysaccharide from Flammulina velutipes. Carbohyd. Polym. 2018, 197, 147-156. [CrossRef] [PubMed]

7. Pang, X.B.; Yao, W.B.; Yang, X.B.; Xie, C.; Liu, D.; Zhang, J.; Gao, X.D. Purification, characterization and biological activity on hepatocytes of a polysaccharide from Flammulina velutipes mycelium. Carbohyd. Polym. 2007, 70, 291-297. [CrossRef]

8. Lin, L.; Cui, F.Y.; Zhang, J.J.; Gao, X.; Zhou, M.; Xu, N.; Zhao, H.J.; Liu, M.; Zhang, C.; Jia, L. Antioxidative and renoprotective effects of residue polysaccharides from Flammulina velutipes. Carbohyd. Polym. 2016, 146, 388-395.

9. Wang, J.; Lian, P.; Yu, Q.; Wei, J.; Kang, W.Y. Purification, characterization and procoagulant activity of polysaccharides from Angelica dahurice roots. Chem. Cent. J. 2017, 11, 1-8.

10. Yin, Z.; Zhang, W.; Zhang, J.; Kang, W. Isolation, purification, structural analysis and coagulatory activity of water-soluble polysaccharides from Ligustrum lucidum Ait flowers. Chem. Cent. J. 2017, 11, 98. [CrossRef] [PubMed]

11. Zhang, X.; Yu, Q.; Jiang, H.; Ma, C.; Kang, W.Y. A novel polysaccharide from Malus halliana Koehne with coagulant activity. Carbohydr. Res. 2019, 485, 1-8. [CrossRef]

12. Wang, L.; Zhang, X.; Niu, Y.; Ahmed, A.F.; Wang, J.; Kang, W. Anticoagulant activity of two novel polysaccharides from flowers of Apocynum venetum L. Int. J. Biol. Macromol. 2019, 124, 1230-1237. [CrossRef]

13. Jia, W.; Feng, J.; Zhang, J.S.; Lin, C.C.; Wang, W.H.; Chen, H.G. Structural Characteristics of the Novel Polysaccharide FVPA1 from Winter Culinary-Medicinal Mushroom, Flammulina velutipes (Agaricomycetes), Capable of Enhancing Natural Killer Cell Activity against K562 Tumor Cells. Int. J. Med. Mushrooms 2017, 19, 535-546. [CrossRef] [PubMed]

14. Ciucanu, I.; Kerek, F. A simple and rapid method for the permethylation of carbohydrates. Carbohydr. Res. 1984, 131, 209-217. [CrossRef]

15. Cui, L.L.; Xing, M.M.; Xu, L.T.; Wang, J.F.; Zhang, X.Y.; Ma, C.Y.; Kang, W.Y. Antithrombotic components of Malus halliana Koehne flowers. Food. Chem. Toxicol. 2018, 119, 326-333. [CrossRef]

16. Wang, L.P.; Ma, Q. Clinical benefits and pharmacology of scutellarin: A comprehensive review. Pharmacol. Ther. 2018, 190, 105-127. [CrossRef] [PubMed]

17. Albert, L.; Soren, R.B.; Jillian, J.S.; Cathy, R.W.; Serge, C. Effects of Yunnan Baiyao on blood coagulation parameters in beagles measured using kaolin activated thromboelastography and more traditional methods. Int. J. Vet. Sci. Med. 2017, 5, 53-56. [CrossRef]

18. Cerna, M.; Barros, A.S.; Nunes, A.; Rocha, S.M.; Delgadillo, I.; Copikova, J.; Coimbra, M.A. Use of FT-IR spectroscopy as a tool for the analysis of polysaccharide food additives. Carbohyd. Polym. 2003, 51, 383-389. [CrossRef]

19. Zhang, J.X.; Chen, M.; Wen, C.T.; Zhou, J.; Gu, J.Y.; Duan, Y.Q.; Zhang, H.H.; Ren, X.F.; Ma, H.L. Structural characterization and immunostimulatory activity of a novel polysaccharide isolated with subcritical water from Sagittaria sagittifolia L. Int. J. Biol. Macromol. 2019, 133, 11-20. [PubMed]

20. Wang, L.; Liu, H.M.; Qin, G.Y. Structure characterization and antioxidant activity of polysaccharides from Chinese quince seed meal. Food. Chem. 2017, 234, 314-322. [CrossRef]

21. Liu, Y.; Zhang, B.; Ibrahim, S.A.; Gao, S.S.; Yang, H.; Huang, W. Purification, characterization and antioxidant activity of polysaccharides from Flammulina velutipes residue. Carbohyd. Polym. 2016, 145, 71-77.

22. Liao, W.Z.; Luo, Z.; Liu, D.; Ning, Z.X.; Yang, J.G.; Ren, J.Y. Structure Characterization of a Novel Polysaccharide from Dictyophora indusiata and Its Macrophage Immunomodulatory Activities. J. Agric. Food. Chem. 2015, 63, 535-544. [CrossRef] 
23. Smiderle, F.R.; Carbonero, E.R.; Mellinger, C.G.; Sassaki, G.L.; Gorin, P.A.J.; Iacomini, M. Structural characterization of a polysaccharide and a $\beta$-glucan isolated from the edible mushroom Flammulina velutipes. Phytochemistry 2006, 67, $2189-2196$. [CrossRef]

24. Li, F.; Wei, Y.; Liang, L.; Huang, L.; Yu, G.; Li, Q. A novel low-molecular-mass pumpkin polysaccharide: Structural characterization, antioxidant activity, and hypoglycemic potential. Carbohyd. Polym. 2021, 251, 1-11. [CrossRef] [PubMed]

25. Meng, Y.; Yan, J.M.; Yang, G.; Han, Z.; Tai, G.H.; Cheng, H.R.; Zhou, Y.F. Structural characterization and macrophage activation of a hetero-galactan isolated from Flammulina velutipes. Carbohyd. Polym. 2018, 183, 207-218. [CrossRef]

26. Zhang, A.Q.; Sun, P.L.; Zhang, J.S.; Tang, C.H.; Fan, J.M.; Shi, X.M.; Pan, Y.J. Structural investigation of a novel fucoglucogalactan isolated from the fruiting bodies of the fungus Hericium erinaceus. Food. Chem. 2007, 104, 451-456. [CrossRef]

27. Cui, D.; Zhao, D.; Huang, S. Structural characterization of a safflower polysaccharide and its promotion effect on steroid-induced osteonecrosis in vivo. Carbohyd. Polym. 2020, 233, 1-10. [CrossRef] [PubMed]

28. Huang, W.; Deng, H.; Jin, S.Y.; Yang, W.B.; Wang, H.L.; Meng, C.Q.; Wang, H.; Yang, S.H. A polysaccharide from dried aerial parts of Agrimonia pilosa: Structural characterization and its potential therapeutic activity for steroid-induced necrosis of the femoral head (SANFH). Carbohyd. Polym. 2019, 214, 71-79. [CrossRef]

29. Cao, J.J.; Lv, Q.Q.; Zhang, B.; Chen, H.Q. Structural characterization and hepatoprotective activities of polysaccharides from the leaves of Toona sinensis (A. Juss) Roem. Carbohyd. Polym. 2019, 212, 89-101. [CrossRef]

30. Wu, M.; Li, W.; Zhang, Y.; Shi, L.; Xu, Z.; Xia, W.; Zhang, W. Structure characteristics, hypoglycemic and immunomodulatory activities of pectic polysaccharides from Rosa setate $x$ Rosa rugosa waste. Carbohyd. Polym. 2021, 253, 1-10. [CrossRef]

31. Su, Y.; Li, L. Structural characterization and antioxidant activity of polysaccharide from four auriculariales. Carbohyd. Polym. 2020, 229, 1-9. [CrossRef] [PubMed]

32. Zhu, R.; Zhang, X.; Wang, Y.; Zhang, L.; Zhao, J.; Chen, G.; Fan, J.; Jia, Y.; Yan, F.; Ning, C. Characterization of polysaccharide fractions from fruit of Actinidia arguta and assessment of their antioxidant and antiglycated activities. Carbohyd. Polym. 2019, 210, 73-84. [CrossRef] [PubMed]

33. Chen, J.J.; Yong, Y.Y.; Xing, M.C.; Gu, Y.F.; Zhang, Z.; Zhang, S.Z.; Lu, L. Characterization of polysaccharides with marked inhibitory effect on lipid accumulation in Pleurotus eryngii. Carbohyd. Polym. 2013, 97, 604-613. [CrossRef] [PubMed]

34. Wang, Y.T.; Liu, Y.F.; Yu, H.Z.; Zhou, S.; Zhang, Z.; Wu, D.; Yan, M.Q.; Tang, Q.J.; Zhang, J.S. Structural characterization and immunoenhancing activity of a highly branched water-soluble beta-glucan from the spores of Ganoderma lucidum. Carbohyd. Polym. 2017, 167, 337-344. [CrossRef] [PubMed]

35. Lu, M.K.; Cheng, J.J.; Lin, C.Y.; Chang, C.C. Purification, structural elucidation, and anti-inflammatory effect of a water-soluble 1,6-branched 1,3- $\alpha$-d-galactan from cultured mycelia of Poria cocos. Food. Chem. 2010, 118, 349-356. [CrossRef] 